\title{
ESTRATEGIA DE NEGOCIOS PARA EXPORTAR PRODUCTOS AGRÍCOLAS DESDE COSTA RICA
}

MONSERRAT ESPINACH RUEDA

Universidad Estatal a Distancia, Costa Rica

mespinach@uned.ac.cr

\section{RESUMEN}

A partir de la experiencia de la autora, en más de diez años comercializando productos agrícolas a mercados de Europa, Estados Unidos y Canadá, añadido a la experiencia de seis años impartiendo cursos en la Escuela de Administración de la Universidad Estatal a Distancia de Costa Rica, se ha detectado una necesidad del estudiante, futuro administrador, deconocersobrecomercialización internacional desde la perspectiva del exportador. Utilizando una metodología cualitativa, se detallan los supuestos de la realidad percibida por la autora, respaldada con revisión bibliográfica que fundamente la teoría presentada. Bosquejando los elementos que dificultan a las empresas agrícolas expandirse a mercados externos, se propone como objetivo principal determinar la mejor estrategia a seguir para exportar productos agrícolas perecederos con la finalidad de presentar al futuro administrador-exportador un legado de conocimiento de la forma correcta de accionar en la planificación de los negocios internacionales agrícolas de Costa Rica.

PALABRAS CLAVE. EXPORTACIÓN, NEGOCIOS INTERNACIONALES, PRODUCTOS AGRÍCOLAS.

\section{ABSTRACT}

Based on the author's experience of more than ten years exporting fresh agricultural products to markets in Europe, the United States and Canada, added to the experience of six years imparting courses at the School of Administration of the Distance State University (UNED) from Costa Rica, it has been detected a student need, a future administrator, to know and learn about international marketing from the perspective of the exporter. Using a qualitative methodology the assumptions of the reality perceived by the author are outlined, backed with a literature review that supports the theory presented. This article proposes as it main objective to establish the best strategy to follow to export perishable agricultural products, by detailing the elements that make it difficult for an agricultural company to expand in external markets, with the aim of presenting to the future administrator-exporter, a legacy of knowledge of the correct way to operate in the planning of the international agricultural business from Costa Rica.

KEY WORDS. INTERNATIONAL BUSINESS, EXPORT, FARM PRODUCTS 


\section{INTRODUCCIÓN}

La exportación de productos agrícolas dista de cualquier otro tipo de exportación de insumo no perecedero. La variable durabilidad en agricultura es de suma importancia al momento de exportar. El producto fresco tiene una vida útil corta y estrecha las brechas de tiempo al momento de producir y vender la cosecha; por consiguiente, los productos agrícolas requieren una estrategia de ventas y producción diferente.

El presente artículo pretende resumir la mejor estrategia a seguir por un empresario agrícola que pretenda expandir su negocio al mercado de exportación, que le permita competir en el mercado externo. La fuente de información principal será la experiencia de la autora, quien durante más de diez años laboró como gerente de exportaciones en una empresa agrícola dedicada a la producción y exportación de café, mini vegetales y la comercialización de melón, piña, papaya, rambután, arveja china, mora y tubérculos a los países de España, Alemania, Holanda, Estados Unidos y Canadá.

A partir de una acción exploratoria bibliográfica, de la experiencia en campo y de la práctica profesional, se detallan los hechos de la realidad percibida por la autora con fundamentos teóricos que respalden el objetivo principal de estudio, que será determinar la mejor estrategia competitiva a seguir en una empresa agrícola para poder exportar. La finalidad del estudio es servir de insumo de información para futuros graduados de administración de empresas con especialidad en negocios internacionales y empresarios que tengan planes de exportar productos agrícolas.

\section{Aspectos básicos de la exportación en Costa Rica}

Una exportación es toda aquella operación de salida de bienes o productos del territorio na- cional hacia otro país, que debe cumplir con los requisitos legales para comercializar fuera de las fronteras nacionales (Ministerio de Hacienda de Costa Rica, s. f.). La exportación de un producto se da cuando hay demanda externa al territorio nacional de ese bien. Conocer un nicho de mercado fuera de las fronteras nacionales involucra un proceso de inteligencia comercial competitiva, en donde la figura del exportador es la clave del éxito para lograrlo, al integrar un análisis del entorno con la finalidad de reducir las incertidumbres del mercado (García y Ortoll, 2017).

Cuando se tiene la idea de exportar, lo primero que se debe hacer es detectar los posibles nichos externos del mercado del producto. Esto se logra a partir del análisis del entorno de los países tanto productores como compradores. Asesoría de organismos gubernamentales como la Cámara de Comercio Exterior (CADEXCO) y la Promotora de Comercio Exterior de Costa Rica (PROCOMER) mejoran la búsqueda de identificación de clientes potenciales, pero la alianza estratégica que pueda surgir en una negociación y la clave del éxito de la negociación le corresponde al exportador forjarla. Una alianza estratégica es "cuando dos o más empresas integran una asociación o consorcio temporal con el propósito de aprovechar alguna oportunidad" (Fred, 2003, p. 177); por consiguiente, es la figura del exportador, quien conciba con su futuro cliente arraigar la negociación.

\section{REFERENTE A LA SALIDA DE PRODUCTOS AGRÍCOLAS DE COSTA RICA}

La salida de productos agrícolas en Costa Rica está regida por el Reglamento y Ley General de Aduanas de Costa Rica (RLGA), la cual regula tanto exportaciones como importaciones. A nivel nacional, la Dirección General de Aduanas (DGA) es el ente regulador a cargo de propiciar el trasiego de mercaderías (Ministerio de Hacienda de Costa Rica, s. f.). 
En Costa Rica, el artículo 8 de la Ley General de Aduana No8373 indica que las instituciones públicas encargadas de velar por el control del comercio exterior son el Ministerio de Hacienda y el Ministerio de Comercio Exterior, los cuales dispondrán, a través de la Dirección General de Aduanas, del personal necesario para cumplir con todos los acuerdos y tratados comerciales vigentes (Sistema Costarricense de Información Jurídica, s. f.).

La figura del exportador es la "Persona física o jurídica que efectúe al menos 12 exportaciones al año cumpliendo con los requisitos y obligaciones estipulados en el RLGA y autorizado como tal por la DGA al amparo de la legislación vigente" (Dirección General de Aduanas s. f.). Es importante, al ser exportador agrícola, estar inscrito ante el Ministerios de Agricultura y Ganadería (MAG) en la Oficina de Fitosanitarios. Ahí, se deben cumplir lineamientos legales de insumos utilizados en agricultura para el control de plagas y enfermedades permitidos.

\section{Planeación estratégica en empresas agrícolas de exportación}

La planeación estratégica implica administrar una organización a partir de un "proceso que permite la identificación de oportunidades de mejoramiento en la operación de organización con base en la técnica y el establecimiento (...) de planes [para aprovechar] oportunidades" (Aguilar, 2000, p. 19). La importancia de una exitosa planeación estratégica consiste en el grado de involucramiento que logre la alta gerencia en desarrollar en su personal un compromiso de empoderamiento, en poder transmitir y ejecutar las metas y prioridades de la organización conociendo todo el personal involucrado todo lo que debe saber para hacer lo mejor y lo más requerido para ejecutar las mismas (Covey, 2011).
Para conseguir una planeación estratégica, se debe definir una estrategia a seguir que permita crear una ventaja competitiva con respecto a la competencia que se tiene en el mercado. Según Porter (2010), la competencia de un mismo producto o servicio trae consecuencias en el precio. La estrategia es buscar nuevas formas de competir que permitan crear un valor agregado que genere nuevas rentabilidades a una organización, recordando que no es estrategia comprar nuevas máquinas o usar nuevas formas de comunicación con el cliente, ya que esas son necesidades para suplir de una mejor forma lo que requiere el cliente con el producto o servicio que se tiene actualmente. Estrategia es buscar algo nuevo; crear fuentes de valor para la organización que la diferencien tanto de lo que hace actualmente como de la competencia.

Exportar es el último paso que debe seguir una empresa agrícola. Antes, debe tener una estrategia de comercialización definida. Una organización bien fundamentada debe tener un plan a seguir de todas las partes que involucran el proceso. "La planeación estratégica es la planeación global, general, que precede a la planeación operacional, más detallada" (Everett y Ebert, 1991, p. 42). En empresas agrícolas, es necesario tener manuales de producción según el cultivo que se siembra.

Los manuales de producción agrícola son procedimientos en donde se tiene estimado los costos detallados por hectárea, se tiene la cantidad de producción estimada a producir, el ciclo de vida del cultivo y sus distintas etapas de abonar y fumigar el cultivo para el control de plagas y enfermedades. En exportación agrícola es requerido el control de plaguicidas y enfermedades, tanto para cumplir con normativas nacionales dictadas por el MAG como por lineamientos legales de países externos.

Cuando se indica la importancia en exportación agrícola que se da al control de plagas y enfer- 
medades, es importante conocer la conceptualización del término de plaga como "todo animal que causa daño a un cultivo. Las principales plagas son: insectos, arañas, babosas (moluscos) y nematodos" (Ramírez, 2004, p. 56). Las enfermedades en las plantas se dan por una interacción de éstas y el medio ambiente que interactúan (Ramírez, 2004).

En agricultura, se requiere utilizar productos químicos en producciones que no son orgánicas para mitigar el impacto de las estas; se rigen por reglamentaciones fitosanitarias ${ }^{1}$ a cumplir para enviar a países con regulaciones especiales. Conocer el grado de toxicidad en tiempos de aplicación, periodo de descanso del producto antes de ser cosechada la siembra, permite tener un mejor control de enfermedades y plagas en las plantaciones y a la vez cumplir con los reglamentos estipulados para exportar.

Las empresas deben tener manuales de procesos que faciliten la información necesaria para que el productor tenga la estimación de tiempos de espera requeridos. Esto le evitará sufrir consecuencias graves como la destrucción de embarques de exportación o exponer un embarque a un periodo de cuarentena por utilizar productos no permitidos en las siembras, que pueden llevar al cierre definitivo de negociaciones bilaterales entre países por incumplimiento de reglamentaciones fitosanitarias entre países.

En aspectos monetarios, antes de exportar es requerido medir la capacidad financiera de la empresa para poder incurrir en gastos nuevos como: costos relacionados con la logística y transporte; empaque y etiquetado; crédito con clientes; promoción. Definir estos aspectos y saber con antelación hasta dónde llega la capacidad de la empresa influirá en el éxito exportador. Esto porque aunque existen muchas formas de financiar crédito con clientes de mercado externos como son las cartas de crédito que asegu-

1. Ley No7664. Ley de Protección Fitosanitaria. ran el pago de una factura comercial, en el diario vivir de una negociación constante de exportación, el factor crédito que se ofrece al cliente es clave del éxito en las negociaciones de exportación agrícola.

\section{DEFINICIÓN DE LA MEJOR TEORÍA COMPETITIVA PARA COMPETIR EN EL MERCADO DE EXPORTACIÓN AGRÍCOLA}

Para que una empresa pueda crecer y sostenerse en el tiempo es importante que defina su estrategia de negocios; esta va enfocada a la misión y visión de cada negocio. La estrategia Andrews (1977) define los "planes esenciales para la consecución de dichas metas, establecidos de tal manera que definan en qué clase de negocio la empresa está o quiere estar y qué clase de empresa es o quiere ser" (p. 59).

Una estrategia Castro (2010) es la "dirección en la que una empresa necesita avanzar para cumplir con su misión" (p. 249). Autores como Mintzberg (1978) ven la estrategia como el flujo de decisiones que permite crecer a una empresa y, según Miles y Snow (1978), todo crecimiento de una empresa va definido por la adaptación que esta tenga con el entorno en que se desenvuelve. "La estrategia constituye la principal directriz del comportamiento empresarial y puede condicionar de forma notable el resultado alcanzado por la organización" (p. 248). Conocer los distintos tipos de estrategias competitivas y adecuar el mejor modelo a la empresa es importante para cumplir las metas de la organización.

De los autores más importantes en definir teorías de estrategias competitivas, según Castro (2010, p. 249) se encuentran cinco: "Miles and Snow (1978), Porter (1980), Miller (1987), Mintzberg (1988) y Kotler (1992)". A continuación, se detallan los principales aportes de cada teoría para posteriormente analizar cuál es la mejor estrategia a considerar para exportaciones agrícolas. 
Para hacer una planificación estratégica eficaz es necesario tener una. Esta es "la determinación de las metas y objetivos de una empresa a largo plazo, las acciones a emprender y la asignación de recursos necesarios para el logro de dichas metas" (Contreras, 2013, p. 161, citado en Chandler, 2003). Cuando se tienen definidos los objetivos de la organización con metas claras a corto y largo plazo, la estrategia y los planes de acción a seguir son la base que permite lograr los objetivos de la empresa.

Una empresa debe enfocar su estrategia al control de insumos, consumidores o mercado estratégico, mercado competidor y a la industria relacionada al negocio. Esto implica identificar las necesidades del cliente, lograr una diferenciación de la competencia y tener un liderazgo en costos. Estas son las claves de la competitividad y, según Aguilar (2000), son las bases estratégicas genéricas de las negociaciones que son instruidas por Michael Porter.

Tener una identificación del cliente potencial es el enfoque que permite determinar el camino a seguir para conquistar y mantener en el tiempo ese nicho de mercado. El liderazgo en costos de una va de la mano de un concepto de productividad que involucra producir con la mayor eficacia y eficiencia del sistema (Robbins, 2004, p. 21). Visualizar una estrategia implica definir planes de acción que permitan identificar las necesidades de las personas que deben ser suplidas por la organización dentro del mercado que participa (Mata, 2007).

Es importante el análisis de hábitos de consumo, idiosincrasia, creencias, aspectos culturales característicos de cada región y las restricciones de un determinado producto o servicio para conocer los agentes externos que afectan el desempeño interno de una organización. Aspectos internos de la organización van relacionados con la planeación interna y la interacción que surgen entre todas las áreas de la organización y permi- ten crear un mayor valor agregado a lo que ofrece la competencia. A continuación, se detallan los principales aportes de cada teoría para, posteriormente, analizar cuál es la mejor estrategia a considerar para exportaciones agrícolas.

- Estrategias competitivas

de Miles y Snow (1978)

Miles y Snow (1978, p. 27) se basan en tres premisas. Primero, indican que las empresas tienen un "ciclo adaptativo" en donde las organizaciones enfrentan distintos problemas de índole interno y externo al campo de acción, muy relacionados con su estructura organizativa y de producción. La segunda premisa se enfoca al comportamiento diferente de las distintas industrias del mercado. Se realizaron experimentos de campo para descubrir los comportamientos de "empresas electrónicas, proceso de alimentos, salud y libros de texto" y, posteriormente probada en numerosos estudios, se confirma que cada industria tiene diferentes formas de proceder organizativamente y de competir según el sector al que se dirige (Castro, 2010, p. 254).

Según Castro (2010), se lograron definir cuatro campos de acción dentro de las empresas, en donde se ubican las empresas de carácter prospectivo que están enfocadas a la innovación. Empresas con una tendencia a la defensiva se mantienen intactas en el tiempo; lo que producen, lo mantienen en el tiempo e ignoran innovar. Empresas analizadoras actúan de manera prospectiva y a la defensiva; su comportamiento es ver que está haciendo la competencia para hacer lo mismo después. Por último, el campo de acción reactivo en donde la empresa reacciona a lo que sucede en el medio pero lo hace sin una estrategia definida que no le permite definir un trayecto estable a seguir. 


\section{- Estrategias competitivas de Porter (1980)}

La estrategia de Porter conceptualiza la definición de ventaja competitiva a partir de una estrategia de diferenciación, competitividad en liderazgo de costos y enfoque. Este se percibe como una estrategia que contempla ser líder en creación de un valor agregado a un nicho de mercado identificado.

La estrategia de diferenciación, entendida como una forma de hacer las cosas, puede percibir diferencias significativas que permiten crear un valor agregado y permite a la empresa lograr crecer en el sector en el que se desarrolla. La estrategia busca superar la media del promedio de cualquier actividad realizada (Castro, 2010). Ser líder en costos implica ser parte de una estrategia de diferenciación que permite crear planes de acción a seguir para generar una mejora continua y un mejor desarrollo de los procesos de la empresa en miras de buscar ser el competidor mejor posicionado (Hill y Jones, 1996).

\section{- Estrategias competitivas de Miller (1987)}

La estrategia de Miller define la estructura de una estrategia como la mezcla de innovación, diferenciación de marketing, amplitud y control del costo (Robbins, 1990 citado en Castro, 2010). La innovación se dirige hacia los productos, procesos, desarrollo de productos, ingeniería en innovación y desarrollo de productos nuevos (Pérez y García, 1997).

\section{- Estrategias competitivas de Mintzberg (1988)}

Mintzberg critica la estrategia de Porter, separando "focalización de diferenciación y liderazgo en costes argumentando que la primera define el ámbito del mercado mientras que las otras estrategias de Porter reflejan la manera en que compite la empresa en ese mercado" (Mintzberg, 1988, citado en Castro, 2010, p. 265). Se- gún Castro (2010) las estrategias de Mintzberg se dividen en seis tipos de estrategias.

La primera estrategia es la indiferenciación, conocida como las empresas que copian a la competencia porque no tienen características que las diferencie; después, diferenciación en imagen, en donde a partir de la publicidad se busca mantener al cliente fiel al producto o servicio; luego, la diferenciación en calidad, la cual busca un valor agregado de lo que se ofrece y permite hacer la diferencia con la competencia. La cuarta estrategia es la diferenciación en diseño, que busca un desarrollo e innovación constantes en la empresa; también, está la diferenciación en precio, se da siempre que existan costos bajos. Por último, se encuentra la diferenciación en soporte, que permite crear un servicio personalizado y de calidad al cliente.

\section{- Estrategia competitividad de Kotler (1992)}

La importancia de evaluaciones realistas de las fuerzas del mercado hacen que se definan en el modelo de Kotler "cuatro tipos de estrategias competitivas según la participación de mercado: las estrategias del líder, del retador, del seguidor y del especialista" (Kotler, 1992 citado en Castro, 2010, p. 267).

En la estrategia del "líder", la empresa se caracteriza por dominar el mercado en participación de los clientes que le permiten dominar más que la competencia. La estrategia "retador" está fundamentada en que la competencia no domina al líder pero está cerca de este, en posicionamiento de mercado. La misma crea estrategias que le permitan crecer para retar al líder. La estrategia del "seguidor" es la "coexistencia pacífica" de las competencias en donde existe un respeto entre empresas. La estrategia "especialista" o "enfoque" es la que se especializa en un segmento del mercado (Castro, 2010, p. 270). 


\section{Análisis de estrategias para determinar la mejor estrategia a seguir para exportar productos agrícolas}

La teoría de Miles y Snow (1978) indica que las empresas atraviesan un "ciclo adaptativo" (p. 27), pero en exportación no es permitido adaptarse el cambio constante. Es necesario ser ingenioso e innovar para permitir mejorar la calidad del producto. Se acepta la premisa de que cada industria del mercado tiene un enfoque diferente y se descarta la premisa del comportamiento reactivo de las empresas, por motivo de que hay una necesidad imperante de ser proactivo en exportación agrícola. Con respecto a la teoría competitiva de Porter (1980), se define la estrategia a partir de la diferenciación, liderazgo en costos y enfoque a ser líder en tener un valor agregado a un nicho de mercado definido.

Todas las estrategias del modelo de Porter son requeridas en la estrategia de comercialización de productos agrícolas para exportación, ya que en agricultura no se puede pretender producir todo tipo de cultivo. Es requerido enfocarse en el cultivo mejor adaptado al clima, terreno y lugar. Cada siembra tiene condiciones especiales de producir en donde la naturaleza juega un papel imperante en la calidad del cultivo.

Para dar un ejemplo de lo anterior, se podría detallar el cultivo de uvas. La producción de uvas es mejor en terrenos con condiciones de sequía, con noches frías y días muy calurosos (Tonietto, Sotés y Gómez, 2012). Países como Costa Rica no son aptos para el cultivo de uva porque no tiene el clima adecuado para esta labor. Lo que sucede es que la uva producida en terrenos con esas características climáticas tendrá menos acidez que una uva producida en Costa Rica, será de mayor calidad la fruta en sabor y tamaño $y$, al estar el fruto expuesto a sus condiciones de cultivo, producirá una mayor cantidad. Factores como tipo de tierra, condiciones climáticas, altitud, cantidad de precipitaciones, entre otros, hacen que una misma semilla tenga un sabor y cantidad de producción diferente al ser cultivada en lugares con características distintas.

En agricultura se puede sembrar la misma semiIla, tener el mismo programa de fertilización, de control de plagas y enfermedades y el mismo cuido del cultivo; pero la naturaleza se encarga de dar la variante de diferenciación en los cultivos. Es importante que un empresario agrícola identifique cuál es el cultivo o cultivos que puede producir según la zona de procedencia en que tiene su terreno para que se especialice en aquellos que le sea rentable producir. La ayuda de un ingeniero agrónomo o buscar información en el MAG, le permitirá al productor nacional salir avante en un negocio agrícola.

Miller (1987) adapta muy bien la teoría de Porter (1980) y de Miles y Snow (1978), pero el grado de creación de nuevos productos hace que sea útil en otros tipos de negociaciones o de industria. En agricultura, el grado de innovación que dicta Miller lo genera la diferenciación que se debe tener y la realidad de la agricultura es que se requiere ser especialista del cultivo que se pueda producir.

Una estrategia de crear nuevos cultivos que, por condiciones de la naturaleza no se podrán producir, no es rentable en agricultura. Por tanto, aunque la teoría de Miller sí puede ser aplicada en comercio de agricultura para exportar, hay variantes que se deben considerar a la estrategia de implementación y es preferible mantener el criterio de Porter al enfocarse en ser líder en costos y diferenciación de un nicho de mercado específico.

Por su parte, la estrategia de Mintzberg (1988) dista de servir a nivel de agricultura para exportación porque divide a las empresas por grados de diferenciación. En este sistema, a como existen empresas que no crean ni gestionan ninguna diferencia con la competencia, hay otras que se diferencian en dar más peso a la imagen, diseño, precio y soporte. 
Algunas de las estrategias sí son requeridas en los negocios internacionales, como una estrategia de diferenciación en calidad y precio pero una diferenciación de imagen aplicada a publicidad o buen diseño de empaque para los productos agrícolas sin calidad de producto queda sin efecto para un negociador de productos agrícolas perecederos. En negocios de exportación es un error determinar que una empresa simplemente se adapta a la competencia y continúa sin ninguna estrategia de diferenciación.

Por último, en el análisis de la estrategia de Kotler, esta tiene cuatro estrategias competitivas para participar del mercado: la de ser líder de un mercado; retar a la competencia con la finalidad de dominarla; la de seguidor, que permite hacer lo que hace la competencia; y la de especialista o enfoque a un segmento del mercado (Castro, 2010). La estrategia que se aplica en los negocios de exportación agrícola es la de enfoque a un segmento del mercado; las otras estrategias indicadas sirven en negocios industriales y comerciales. Es una teoría muy sólida, pero no aplicable en su totalidad a negocios agrícolas, en el sentido que la estrategia de ser líder del mercado en agricultura es imposible porque el mercado lo domina la relación de la oferta y demanda.

Por ejemplo, países productores de café como Costa Rica no pueden ser líder del mercado ante un cultivo en donde los precios internacionales son dictados por lo que suceda en otras naciones productoras y el efecto del comportamiento de consumo de las personas a nivel mundial. Un cambio climático en Brasil o Colombia, que también producen café, puede hacer bajar los precios internacionales o subirlos; todo depende de cuánto café hay en el mercado y cómo se encuentra el consumo de él.

\section{Estrategia de competitividad para aplicar en empresas de exportación agrícola}

Al analizar los modelos descritos anteriormente, estos tienen pautas y formas de definición de estrategia distintas, pero existe un común denominador y es la necesidad de las empresas de sostenerse en el mercado actual. Con respecto a la mejor estrategia a definir para exportar productos frescos, el modelo que cumple con las expectativas de lo que requiere el futuro exportador agrícola es la estrategia de Porter.

El modelo de Michael Porter, también Ilamado "Diamante de la Competitividad", con su estrategia de liderazgo en costos y diferenciación y enfocado a especilizarse en un nicho de mercado específico, permite dirigir la estrategia a seguir a un control de insumos, consumidores o mercado estratégico, mercado competidor y a la industria relacionada al negocio (Rozas, Corredor, Lombana, Silva, Castellanos, González, y Ortíz, 2013, p. 206).

Al momento de exportar, lo importante es tener una idea del mercado potencial del producto que se desea enviar el producto. La clave del éxito al exportar radica en identificar las necesidades del cliente, lograr una diferenciación de la competencia y tener un liderazgo en costos que permitan ser competitivo; por tanto, es necesario permitir crear "bases genéricas" en las negociaciones (Fred, 2003, p. 175) y permite, según Aguilar (2000), "una identificación de oportunidades de mejoramiento en la operación de la organización" (p. 19) que le genera una mayor competitividad.

Tener una identificación del cliente potencial es el enfoque que permite determinar el camino a seguir para conquistar y mantener en el tiempo ese nicho de mercado. Los clientes se consiguen por una fuerte competencia en precios y calidad de producto. El liderazgo en costos de una empresa agrícola va de la mano de un concepto de "productividad" que involucra producir con la mayor eficacia y eficiencia del sistema (Robbins, 2004, p. 21). 
La diferenciación de productos se da cuando "dos o más productos están diferenciados entre sí (...) [y se distingue el producto] de un vendedor de los de otro. Tales diferencias (...) son significativas en tanto revistan importancia para algún comprador y conduzcan a la preferenica de una variedad de producto sobre alguna otra" (López, 1986, p. 29).

El modelo de competitividad de Porter, aplicado en productos agrícolas, consiste en emplear continuamente una reingeniería del proceso. Esta es "la revisión fundamental y el rediseño radical de proceso para alcanzar mejoras espectaculares en medidas críticas y contemporáneas de rendimiento, tales como costos, calidad, servicio y rapidez" (Bravo, 1998, p. 151).

La calidad de producto se da en aspectos de durabilidad, inocuidad, control de plagas y enfermedades, servicio al cliente en aspectos de diferenciación en tiempos de entrega, posibilidad de abrir líneas de crédito a los clientes a partir de utilizar el factoring ${ }^{2}$, mejores precios a la competencia crean una ventaja competitiva con respecto a productos similares que ofrecen otros países y sostienen en el tiempo un nicho de mercado para exportar. Controlar estos aspectos hace una gran diferencia dentro del mercado competidor. La estrategia de diferenciación"se fundamenta en hacer todo lo necesario para diferenciar los productos de aquellos ofrecidos por los competidores, con el propósito de poder cobrar un precio superior" (Hill y Jones 1996, p. 107).

En el modelo de competitividad de Porter existen factores endógenos de difícil control. Se requiere trabajar con planes de acción a seguir y evaluar las implicaciones que tienen las decisiones de los gobiernos involucrados entre los países negociadores. Según Porter, una variable

2. Factoring: "Instrumento de financiación a corto plazo, destinado a todo tipo de empresas". Recuperado de http://www.factoringasociacion.com/factoring que afecta las negociaciones es "el azar", conocido como esas predispocisiones de cambio climático, plagas no controladas por el ser humano que afectan la competitividad (Rozas et al., 2013, p. 210).

\section{Adaptación del modelo de competitividad de Porter para empresas de exportación agrícola}

El modelo de competitividad de Porter se define gráficamente en la figura 1. Una empresa lidia con factores internos y externos que afectan la toma de decisiones, la afecta el gobierno con todas las regulaciones que se aplican al negocio y la afecta el azar, percibido como esa incertidumbre de los negocios de situaciones que no se sabe que pueden suceder como por ejemplo un huracán o un terremoto que afecte el funcionamiento de una empresa.

\section{FIGURA 1 \\ MODELO DE COMPETITVIDAD DE PORTER}

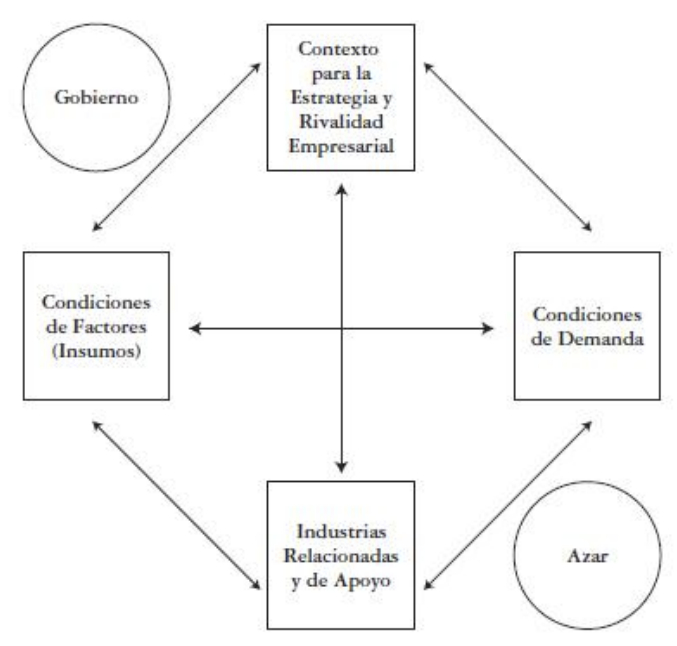

Fuente: Lombana y Rozas (2009, p. 13). 
A continuación, se explica cómo el modelo presentado en la figura 1 se adapta a una empresa exportadora y cómo un empresario debe actuar antes de exportar un determinado cultivo:

- Contexto para la estrategia y rivalidad empresarial. El modelo se inicia a lo interno de la empresa exportadora en aspectos propios de la ella, como el cumplimiento de metas y objetivos propuestos. A partir de esto, se analiza el entorno, que envuelve tanto el mercado competidor como la demanda potencial y esperada. Es importante tener identificado el costo del producto para poder determinar diferentes pautas de negociación según el volumen de producción.

- Condiciones de demanda. El análisis del entorno previo permite determinar la competencia real para la empresa referente a cuáles países producen lo mismo que se planea exportar, volúmenes de ventas y precios internacionales durante un año calendario. La importancia de hacer un análisis histórico de precios internacionales de productos agrícolas es que permite identificar puntos de entrada clave de la producción a exportar.

- Industrias relacionadas y de apoyo. La entrada de un producto agrícola a un determinado país debe hacerse aplicando inteligencia comercial, que es una estrategia de mercadeo que permite determinar las mejores oportunidades de negocios para lo que se planea exportar. Se organiza a partir de la ayuda de organismos y entidades de apoyo al exportador, una estrategia de apertura al nuevo mercado de exportación, lo que permita involucrar a las partes interesadas en la negociación. Entidades gubernamentales como CADEXCO y PROCOMER permiten aligerar el proceso de negociación a partir de insumos de servicios que ofrecen al exportador como son par- ticipaciones a distintas ferias internacioanles, agendas de negocios, entre otras.

- Condiciones de factores (insumos). A partir de involucrar los factores (insumos) determinados en la empresa con las necesidades del cliente y cumplimientos de reglamentaciones gubernamentales (gobierno), se logra una interaccionan en la negociación, en donde se define cuándo se inicia el proceso de exportación o si, por el contrario, es mejor desistir de una negociación futura.

- Gobierno. Involucra todas las reglamentaciones y tratados bilaterales entre países que permiten que una negociación se efectúe o que, por razones de discrepancias en reglamentos o regulaciones se finiquite. Un ejemplo de cómo afecta una negociación el gobierno se dio en el año 2016 en Costa Rica, cuando por factores sanitarios no se permitió la entrada de aguacate de México al país.

Eso afecta, en este caso, a la empresa de México que estimaba vender su aguacate en este país y de repente le cerraron las negociaciones de entrada. En exportaciones agrícolas, el factor gobierno es necesario considerarlo con importancia porque las regulaciones entre países, sobre todo fitosanitarias, son muy estrictas. Si una empresa exporta un producto agrícola que contenga residuos de plagicidas no permitidos por el MAG y ese producto sale fuera de las fronteras de Costa Rica, el país receptor o importador podría castigar todo el producto procedente de un país determinado si descubre la falla del producto y de forma continua. Es decir, la empresa no solo infracciona, sino que afecta a los demás exportadores y ese fue el caso de México con el aguacate que mandó a Costa Rica.

La importancia de que el futuro exportador esté alineado con las regulaciones de cada 
país que piensa exportar es necesario para el exíto de la negociación bilateral. En Costa Rica, el MAG es de gran ayuda para el cumplimiento de esa labor a nivel nacional a través de la Oficina de Fitosanitarios.

- Azar. Percibido como esa incertidumbre del mercado por factores que no se pueden controlar, como son los eventos naturales o guerras, entre otros, que puede afectar a un negocio de agricultura. Esta variable es determinante porque los cultivos, al ser expuestos a condiciones naturales, los cambios en cantidad de precipitaciones, aumento de humedad, hacen que exista una mayor incidencia a enfermedades y plagas en las plantaciones que en casos extremos pueden hacer perder una cosecha.

Un exportador debe llevar un estudio de porcentajes de humedad y precipitaciones de la región donde siembra y adecuar sus sistemas de producción a las condiciones climáticas. Un control histórico de los factores climáticos disminuye el riesgo de pérdida de cosechas y permite mitigar los efectos del "azar" presente en todos los negocios, pero que en agricultura afecta directamente la producción y constancia en la negociación. Como se detalla en la figura 1, el modelo es contanste y retroalimentativo, ya que el conocimiento que se genere de una negociación, culmina en una mejora continua del proceso para otras exportaciones que se realicen a futuro.

\section{ESTRATEGIAS DE IMPLEMENTACIÓN DEL MODELO DE PORTERA LAS NEGOCIACIONES DE EXPORTACIÓN AGRÍCOLA DESDE LA EXPERIENCIA DE LA AUTORA}

En empresas de exportación agrícola, la revisión continua del proceso incluye controlar variables específicas como son: tiempos de entrega del producto al cliente final, conocimientos previos de logística internacional y nacional, medios de transporte, manejo de cargas en tiempo y espacio para control del producto, refrigeración y control aduanero, embalaje, crédito a los clientes. Estas combinaciones necesarias y requeridas son las que permiten ser un potencial exportador agrícola. A continuación, se detalla hacia dónde debe dirigirse la estrategia de implementación para negociar productos agrícolas de exportación

A. Aspectos internos a considerar una empresa agrícola exportadora

- Definir la misión y visión de la empresa y hacer todo lo necesario para cumplir con ellas.

- Plantear objetivos de producciones y ventas a corto, mediano y largo plazo.

- Medir la capacidad máxima productiva de la empresa, periodos de descanso de los terrenos agrícolas entre siembras, con el fin de analizar las cantidades que se pueden ofrecer. Se debe calcular que la producción se mantenga constante en el tiempo.

- Conocer el producto que se tiene; especificaciones técnicas; tener manuales de producción; lineamientos internos del personal y capacitarlo en la temática de control y calidad de procesos agrícolas.

La gestión humana y de insumos debe especificar los planes de acción a seguir en las distintas etapas del ciclo de vida del cultivo, para reducir los efectos de mayor cantidad de producción y controlar posibles cuellos de botellas que ocurren en periodos de mayor producción por la curva cíclica de los cultivos que durante su ciclo de vida tienen periodos de mayor producción según la etapa de crecimiento del cultivo. 
- Instruir al personal sobre nuevas medidas de gestión ambiental ${ }^{3}$ y de calidad por los nuevos requerimientos técnicos a cumplir, según los mercados donde se desea exportar.

Cuando se tienen definidos y detallados en un procedimiento a seguir los pasos anteriores, se procede a analizar una estrategia de análisis del entorno.

\section{B. Análisis del entorno}

La finalidad es lograr identificar la forma correcta de posicionar el producto que se espera exportar, a partir de contemplar lo que sucede en todas las partes involucradas en la futura negociación. La globalización obliga a ser cada día más competitivo para sobrevivir en el mercado, es necesaria una retroalimentación constante del entorno nacional y mundial para lograr tener un posicionamiento del mercado.

Visualizar la viabilidad de entrar a determinado mercado se logra a partir de un estudio de los gustos y preferencias de las personas, analizando: hábitos de consumo, idiosincrasia, creencias, aspectos culturales característicos de cada región y las restricciones de acceso de los países con respecto a controles fitosanitarios ${ }^{4}$.

\section{Logística y transporte}

Se trata de conocer sobre transportes y rutas, costo de cargas (marítimas, terrestres, aéreas) según los distintos volúmenes de producción que afectan una negociación. La situación de los precios internacionales de los combustibles y como éstos afectan costos de transportes son concepciones básicas que afectan directamente en la negociación y determinan el rango de ingresos y egresos totales.

3. Gestión ambiental sistema que encierra una sostenibilidad entre desarrollo económico y control del medio ambiente (Blanco Cordero, 2010, p. 35-37)

4. Fitosanitario "perteneciente o relativo a la prevención y curación de las enfermedades de las plantas. Obtenido el 20 marzo 2017 de https://boletinagrario.com/ap-6,fitosanitario,960.html
Es importante conocer y analizar los costos de la competencia. Se debe determinar cuál es el momento preciso de entrada del nuevo producto. La opinión de distribuidores, cadenas de agentes vendedores permite identificar a todo el gremio que está interesado en el producto específico que se planea exportar.

D. Comunicación en las negociaciaciones internacionales

La estrategia de interacción con futuros clientes al exterior debe tener una comunicación flexible que permita una relación en donde ambas partes ganan en la transacción. Ser exportador es un concepto que va más allá de tener un producto para comercializar en el exterior. Es requerido tener una serie de competencias de negociación dirigidas a tener una comunicación flexible y bidireccional que consiga tener un vínculo con el futuro cliente. "La comunicación flexible es la disposición del individuo para comunicar la idea de que el otro posee datos adicionales y alternativas que podrían contribuir de manera significativa" (Whetten y Cameron, 2011, p. 252). La comunicación bidireccional "es un resultado implícito del respeto y la flexibilidad" (Whetten y Cameron, 2011, p. 253).

El futuro exportador debe comprender que la globalización hace tan competitiva la negociación que debe desarrollar habilidades que le permitan comprender lo que ocurre, tanto a nivel nacional e internacional, de la realidad de su producto. Aspectos económicos como precios de los insumos agrícolas, muy relacionados al precio de los commodities o los precios de los combustibles, influyen directamente en los costos de transporte de las cargas.

También, las políticas económicas nacionales e internacionales afectan el tipo de cambio al comercializar en monedas de los países involucrados. Se deben comprender, a su vez, aspectos culturales propios de cada país: la competencia 
y cómo puede afectar esto las metas de la empresa. Todo eso debe conocerse al momento de negociar, para que la comunicación comparta conocimiento implícito que permite entender la situación del negocio al momento de exportar.

\section{E. Involucramiento de la empresa agrícola con entidades de apoyo al exportador}

La forma más confiable de conocer potenciales clientes y posibles mercados meta es a partir de distintas bases de datos que tiene PROCOMER al servicio de importadores y exportadores. Las herramientas de apoyo al exportador permiten evaluar, desde Costa Rica, los potenciales clientes. Existen suscripciones directas de internet como, por ejemplo, la de Blue Book Services ${ }^{5}$ que ayudan a determinar clientes potenciales, ubicarlos y conocer su situación crediticia.

Las herramientas de promoción que ofrece PROCOMER al futuro exportador son claves para el éxito de la negociación. Existen, por ejemplo, la participación a ferias comerciales de productos específicos por sectores involucrados, las misiones comerciales y las agendas de negocios personalizadas.

Las ferias comerciales internacionales son costosas y muchas veces no se logra una negociación fructífera. La competencia es tan grande en esos eventos que dificulta la consolidación de acuerdos entre las partes si las mismas no gestionaron un acuerdo previo a la participación de la feria. Otra herramienta para comercializar son las agendas personalizadas para el futuro exportador, estas tienen mayor valor agregado porque permiten conocer, de forma personal, los potenciales clientes. Es una promoción muy costosa para el exportador, ya que implica trasladarse a las instalaciones del potencial cliente. Sin embargo, la experiencia indica que es necesario el

5. Sitio web: www. producebluebook.com contacto personal para crear un vínculo de mayor compromiso y es de las mejores opciones en el mercado para crear nuevos clientes.

Cuando una empresa agrícola tiene un límite presupuestario para iniciarse en el campo de exportación, puede acudir a negociaciones como las misiones comerciales; estas se realizan todos los años en Costa Rica, en donde potenciales clientes de distintos cultivos vienen a conocer futuros compradores al país. Es la opción más económica para abrir nuevos mercados de exportación. Las misiones comerciales son organizadas por PROCOMER, pero antes de participar de ellas es importante hacer un análisis de las empresas que visitarán al país, en aspectos de confiabilidad crediticia de la empresa; para esto, un análisis utilizando base de datos previas son requeridas antes de negociar. Una gran mayoría de misiones comerciales terminan en fructíferas negociaciones.

\section{Variables que determinan la viabilidad de exportar un producto agrícola}

Cuando se determinan los posibles mercados a ingresar y se tiene una posible base de datos de potenciales clientes, es requerido un análisis de factores internos y externos de las variables que determinarán la viabilidad de exportar. Las principales variables a medir son producto, embalaje, precio, transporte, crédito.

\section{PRODUCTO}

El producto es el bien que se piensa exportar. Con respecto al él, es necesario hacer un Análisis FODA, el cual consiste en hacer "una apreciación de la situación del ambiente interno y externo de una negociación" (Boland, Carro, Stancatti, Gismano, y Banchieri, 2007, p. 57). La Tabla 1 presenta un esquema a seguir de lo que debe comtemplar un análisis FODA del producto que se espera exportar. El análisis FODA del producto 
TABLA 1

ANÁLISIS FODA DE UN POSIBLE PRODUCTO AGRÍCOLA ANTES DE EXPORTAR

\begin{tabular}{|c|c|}
\hline Fortalezas & Debilidades \\
\hline $\begin{array}{l}\text { Determinar las fortalezas en calidad del producto que se piensa exportar } \\
\text { y lo hace competitivo al de la competencia }\end{array}$ & $\begin{array}{l}\text { Análisis de costos, capacidad productiva, financiamiento que puede } \\
\text { crear debilidades ante la competencia. Es necesario determinarlas y co- } \\
\text { rregirlas para ser un exportador exitoso. }\end{array}$ \\
\hline Oportunidades & Amenazas \\
\hline $\begin{array}{l}\text { Identificar, en el caso de productos agrícolas, la mejor época del año } \\
\text { para ingresar a un nuevo mercado. Es importante ingresar a un nuevo } \\
\text { mercado en un momento específico en el que la competencia, por situa- } \\
\text { ciones normales del clima, tenga afectada su producción. Entrar en esas } \\
\text { épocas crea una necesidad en el cliente, su dependencia y permanencia } \\
\text { hacia el producto nacional que se desea exportar. }\end{array}$ & $\begin{array}{l}\text { Análisis de la economía global y regional, problemas de rutas de trans- } \\
\text { porte, situaciones del ambiente como huracanes, tormentas tropicales, } \\
\text { sequías, entre otros, que afectan la producción y puedan originar pro- } \\
\text { blemas en las negociaciones previas. }\end{array}$ \\
\hline
\end{tabular}

Fuente: Elaboración propia.

es crucial para determinar diseño de empaques, presentaciones, marcas, cantidades y precios que va negociar al futuro cliente.

\section{EMBALAJE}

El embalaje o material de empaque para transportar un producto agrícola es una variable que en cierta forma ayuda a determinar el éxito o fracaso de una negociación en aspectos de conservación de calidad del producto. Cada producto agrícola tiene embalajes distintos a utilizar; los pesos de las cajas de exportación varían por cultivo. Existen lugares que prefieren negociaciones de peso diferentes a los de otros. Por ejemplo, en Europa, para comercializar mini vegetales con clientes potenciales, solicitaban embalajes de una libra de peso; mientras que, en Canadá y Estados Unidos, lo solicitan de cinco libras. Esos aspectos hay que considerarlos sobre todo al momento de negociar y los costos que implica para la empresa exportadora.

Con respecto a las normas de etiquetado que se deben cumplir para ingresar a la mayoría de los países a los que se exporta, la mejor guía de etiquetado, aplicable a la mayoría de los países, es la proporcionada por la FDA ${ }^{6}$, agencia del gobierno de los Estados Unidos responsable de la regulación de alimentos (tanto para personas como para animales), suplementos alimenticios, medicamentos (humanos y veterinarios), cosméticos, aparatos médicos (humanos y animales), productos biológicos y derivados sanguíneos.

Para exportar a Estados Unidos y Canadá, toda empresa exportadora se debe regir por lo que indica la FDA. Europa tiene sus propias normas pero todas son muy similares a las facilitadas por la FDA. Aparte de que si se envía a Europa o Asia, la mayoría de las veces los embarques hacen rutas de tránsito por Estados Unidos y, por consiguiente, los embarques deben registrarse y llevar toda la normativa respectiva de etiquetado y trámites de exportación que se aplica en el país.

\section{PRECIO}

La variable precio es de las más importantes al momento de negociar. Es muy tradicional que los clientes fijen sus precios basados en el valor

6. FDA U.S. Food y Drug Administration. Recuperado de: http://www. fda.gov/ 
que dictan las distintas plazas de mercadear productos agrícolas. En Canadá, por ejemplo, estos se rigen a partir de los precios de la plaza de New York más gastos de transporte o Plaza de Toronto. La costa oeste de Estados Unidos rige sus precios según la plaza de Los Ángeles y Chicago y la costa Este rige los precios por lo que indica la plaza de Miami.

En Europa, la plaza que rige los precios es la de Holanda. Las plazas de negociación, o food terminal (terminales de comercialización de productos alimenticios), son centros de acopio donde se almacenan y comercializan los alimentos que proceden de distintos países y son el punto de negociación de clientes potenciales. Un ejemplo de lo que es un Food Terminal en Costa Rica es lo que se conoce como el PIMA-CENADA (Programa Integral de Mercadeo Agropecuario-Centro Nacional de Abastecimiento y Distribucion de Alimentos) en Barreal de Heredia.

En los food terminal se tiene la ventaja de poder comercializar altos volúmenes de producto, pero a precio de mercado, el cual varía con respecto a la oferta y demanda. En estas plazas se tiene la desventaja de que la comisión que cobran los intermediarios o bróker oscila en un 20\% después de gastos de transporte y manejo de carga, por lo que los márgenes de utilidad para la empresa exportadora no son tan altos como cuando se negocia con clientes directos, los cuales compran en cantidades menores pero ofrecen mejores condiciones de precios.

Las negociaciones a precio de mercado no son recomendables todo el año. Si una empresa utiliza este tipo de negociación es importante que identifique momentos del año para comercializar que, en lo posible, la competencia sea mínima, de manera que le permita tener una liquidación aceptable.

En la variable que se está tratando, es importante manejar los precios puestos en destino, que es lo que se requiere al negociar. Cuando se negocia un precio constante, la competitividad se logra al manejar volúmenes, sobre todo cuando se utiliza transporte aéreo en donde las aerolíneas mejoran considerablemente el precio a mayor cantidad de kilos exportados.

Los precios que se negocian por temporada son muy atractivos para el exportador por ser momentos en que la demanda aumenta por fechas especiales; como el día de los enamorados en febrero; el día de la madre en mayo; el día de acción de gracias en noviembre, en Estados Unidos y en Canadá celebrada en octubre; y fechas especiales como navidad. Es importante para el cliente asegurar las ventas y se puede negociar con anticipación de ambas partes producciones mayores a las que se producen habitualmente en fechas de importancia.

La época de navidad, en diciembre, es de alto consumo pero se debe tener cuidado que después de este periodo y durante dos semanas, las ventas agrícolas de exportación bajan, por lo que se debe contemplar eso en la programación de siembras de exportación. Para una empresa exportadora es importante conocer los distintos INCOTERMS o formas de negociación internacionales. Las más comunes y utilizadas en agricultura son precios FOB y CIF.

\section{LOGÍSTICA Y TRANSPORTE}

Al momento de comercializar productos agrícolas se puede transportar el producto de tres formas. Si la exportación es a países centroamericanos, se utiliza el transporte terrestre. Existe una gran cantidad de opciones logísticas, desde camiones refrigerados hasta embarques consolidados, que son contenedores de 40 pies refrigerados. Se compra el espacio que requiera en el embarque y se comparte transporte con diferentes exportadores. Si el volumen de exportación es muy grande, se utilizan contendores completos o medios contenedores que son de 20 pies. 
En segundo lugar, los transportes aéreos se utilizan en rutas fuera de Centroamérica. Se utilizan para transportar productos perecederos de poca duración como son los mini vegetales, la mora, el palmito, entre otros. Las tarifas en transportes aéreos las definen las aerolíneas, ya que estas también aplican descuentos por volumen.

Las cantidades de kilogramos a negociar ayudan a competir en el mercado. Por ejemplo, en transporte aéreo las tarifas varían según los embarques de +120 kg, +300 kg, +500 kg, +1000 kg. Las oscilaciones de precios de gastos de transporte de las aerolíneas, según el volumen, pueden oscilar hasta en \$1 de costo adicional por kilogramo que se exporta y esto afecta la negociación de venta. En el caso de utilizar transporte aéreo, es importante conocer si son vuelos directos o vuelos con escala y averiguar si la aerolínea tiene refrigeración en el aeropuerto que hace escala evita inconvenientes de pérdida de embarques por problemas de refrigeración en el caso de productos agrícolas.

En logística, es importante conocer sobre los aviones cargueros que solo transportan carga y las alianzas que tienen con distintas aerolíneas o transportistas terrestres. Por ejemplo, para exportaciones a Estados Unidos y Canadá, tiene un costo menor utilizar un transporte aéreo carguero que lleve cargas a Miami desde Costa Rica y de ahí se conecta con transportistas terrestres u otra aerolínea. Es importante conocer con antelación las alianzas de transportistas.

Por último, las negociaciones marítimas aplican a productos agrícolas que tienen más durabilidad, como piña, melón o tubérculos, y se negocian contenedores refrigerados enteros de 40 pies o medios contenedores de 20 pies. Es importante conocer los tiempos de tránsito y las escalas requeridas. También existen contenedores sin refrigeración para transportar granos como café, maíz, trigo, entre otros. Estos cultivos tienen un proceso adicional después de cosechado que permite una mayor durabilidad del producto.

Con respecto a las navieras o transporte marítimo es importante, en caso de que se requiera contenedores refrigerados completos, que se determinen con varios meses de antelación los contenedores requeridos y se hagan contratos preestablecidos a partir del cálculo de la cosecha. Esto se da sobre todo en épocas de diciembre a marzo, en las que se da una ventana comercial de exportaciones de melón y se da un déficit de contenedores refrigerados, por lo que es importante asegurarse los espacios con tiempo firmando cartas de compromisos con las navieras.

La información de los transportistas disponibles la puede suministrar la agencia aduanal, pero siempre es importante negociar directamente con los distintos transportistas (aéreos, marítimos y terrestres). Los descuentos que se logran directamente con un transportista aplican a la empresa exportadora, sin importar la agencia aduanal que tramita la exportación.

\section{CRÉDITO A CLIENTES}

La triste realidad en el campo de la exportación es que si no se da crédito a los clientes, ellos conseguirán el producto de otro proveedor. Los clientes en exportación en su mayoría solicitan 30 días de crédito a partir de que el producto llega a destino. Si se ajusta a lo que duran los contenedores refrigerados en llegar a destinos como Canadá y Europa que son tiempos de tránsito de aproximadamente 15 días, se requiere que la empresa gestione un capital de trabajo que le permita sostener créditos de hasta 45 días.

Lo ideal es negociar precios en donde los clientes se encarguen de pagar el transporte en el lugar de término del embarque pero no siempre suceden esas negociaciones y la empresa exportadora le toca asumir desde Costa Rica el costo 
del flete. Una buena estrategia de negociación de crédito permite sostenerse en el tiempo.

Algunas agencias aduanales financian a los exportadores los gastos de transporte. Sin embargo, es importante que una empresa que piensa exportar antes de utilizar los servicios aduanales de determinada agencia consulte directamente con las navieras, transportistas y líneas aéreas la situación crediticia de la agencia aduanal directamente con el transportista. Estos elementos no involucran al exportador, porque si una agencia aduanal tiene problemas de crédito con los transportistas, se afecta directamente la carga del exportador.

\section{CONCLUSIONES}

La globalización hace que la competitividad sea más agresiva y la única forma de abrir nuevos mercados es aplicando una gestión administrativa que facilite la permanencia en los mercados. Esto se logra a través de la aplicación de un valor agregado al bien o producto, crear una ventaja competitiva a partir de la diferenciación.

La estrategia de Porter permite evaluar desde varias perspectivas a una empresa y presentar un plan de acción a seguir que mejore la competitividad. La planificación estratégica que realice una empresa de exportación determinará a futuro el éxito y continuidad de la empresa en el competitivo mercado de exportación.

La esencia de la planeación estratégica está definida por el cumplimiento que se tenga de los planes de acción a seguir que materialicen en utilidades las metas de la empresa. En un enfoque de desarrollo sostenible que implica producir productos agrícolas con medidas que resguarden la sanidad humana y no afecte la naturaleza, aplicar planeación estratégica implica buscar la mayor rentabilidad para la organización de una forma que permita producir con el menor costo posible mitigando y no teniendo daños colaterales para con la naturaleza.

La planeación estratégica ofrece un enfoque de crear valor de una empresa a partir del grado de diferenciación que pueda transmitir a su entorno en productos o servicios novedosos, ingeniosos que permitan crear un valor agregado a la empresa para que compita en un mercado competitivo. También, ofrece un enfoque de crear valor en una empresa a partir del grado de diferenciación que pueda transmitir a su entorno en productos o servicios novedosos, ingeniosos que permiten crear un valor agregado a la empresa para que compita en un mercado competitivo.

Lo novedoso de la planeación estratégica radica en considerar factores internos y externos que permiten identificar a partir de un análisis FODA los puntos de mejora para cumplir con los objetivos de una organización y permiten crear valor agregado a la actividad que se realiza, a partir de crear planes innovadores de acción que contemplen un análisis de entorno que mitigue el efecto de las adversidades o de los factores que hacen perder competitividad en el mercado. La metodología propuesta permite evaluar, desde varias perspectivas, a la futura empresa exportadora y permite presentar un plan de acción a seguir antes de iniciarse en el negocio de exportación agrícola.

La planificación estratégica que realice una empresa de exportación determinará a futuro el éxito y continuidad de ella en el competitivo mercado de exportación. La calidad del producto en exportaciones agrícolas se inicia cuando se prepara el terreno a sembrar y culmina cuando el cliente final recibe el producto y se sienta satisfecho por él. En exportación es importante ubicarse en tiempo y lugar para poder dar el mejor seguimiento al producto. El proceso logístico es clave en el éxito exportador.

Las medidas de prevención que se utilizan en países industrializados y que aplica el Ministerio 
de Agricultura en Costa Rica y el Ministerio de Agricultura y Ganadería buscan, en el tiempo, que la producción agrícola sea para el consumo humano productos no dañinos que sin el control existente puede terminar en enfermedades para los humanos por la cantidad de agroquímicos utilizados en los cultivos.

La figura del exportador es clave en una empresa exportadora agrícola y es la persona que figura como el líder del proyecto. Este lleva, con metas y objetivos definidos, estrategias de entradas a nuevos mercados y mejoras continuas de los procesos con la finalidad de dar una mayor durabilidad y calidad a los productos agrícolas con el fin de conseguir una diferenciación con la competencia.

La competencia no está entre los productores nacionales, sino en el mercado externo. Es necesario crear un vínculo que involucre esa flexibilidad de ambas partes negociadoras (cliente-productor), anidadas a un alto grado de asertividad al negociar para lograr sellar en el cliente final un compromiso ético y seguro en el tiempo.

Es importante recordar que existen muchos países que pueden ofrecer las mismas condiciones de negociación; por tanto, es necesaria la innovación constante para no perder competitividad y ser líder en costos para tener más ventajas para negociar precios. La clave del éxito exportador agrícola se da al tener un valor agregado del producto y poder ofrecerlo a un mejor precio que la competencia especializándose en lo que se cultiva para un nicho de mercado determinado.

Los productores en Costa Rica deben comprender que la competencia no está entre agricultores nacionales; la competencia está afuera del país. Muchas veces, la mejor estrategia de negocios empieza cuando los exportadores de un mismo sector trabajan en equipo en definir producciones, cantidades, programas conjuntos que involucren asesoramiento, innovación tecnológica de producción, planes de mejora continua. Lo ideal sería crear una sola marca país que identifique a todo un territorio como un solo productor.

Para lograr ser competitivo en una marca país de un solo producto nacional es requerido trabajar en equipo con una estrategia definida en planes de acción que deben involucrar al sector productor. Asimismo, contar con organismos gubernamentales de ayuda que permitan realizar una planificación integral de todos los agricultores del país para ser competitivos a nivel internacional.

\section{REFERENCIAS}

Aguilar, C. (2000). La necesidad de la Planificación Estratégica en las organizaciones industriales modernas. Temas de Ciencia y Tecnología, 4(11), 17-28.

Andrews, R. (1977). El Concepto de estrategia de la empresa. España: Eunsa.

Blanco, M. (2010). Gestión Ambiental camino al Desarrollo Sostenible. San José: Universidad Estatal a Distancia.

Boland, L., Carro, F., Stancatti, M., Gismano, Y., y Banchieri, L. (2007). Funciones de la Administración Teoría y Práctica. Bahía Blanca: Ediuns.

Bravo, R. (1998). Calidad Total. San José: EUNED.

Castro, E. (2010). Las estrategias competitivas y su importancia en la buena gestión de las empresas. Revista Ciencias Económicas, 28(1), 247-276.

Covey, F. (2011). Planeación Estratégica. Recuperado de https://www.youtube.com/watch?v=iiG6Aqus-qo

Contreras E. (2013). El concepto de estrategia como fundamento de la planeación estratégica. Pensamiento y Gestión, 35. Universidad de Colombia, pp.152-181

Dirección General de Aduanas. (s. f.). Procedimiento de exportación. Recuperado de https://costarica. eregulations.org/media/direcci\%C3\%B3n\%20 gnral\%20aduanas.pdf 
Everett E., y Ebert, R. (1991). Adminsitración de la producción y las operaciones. México: Pearson.

Fred, D. (2003). Conceptos de Administración estratégica. México: Pearson Educación.

García, M., y Ortoll, E. (2017). Inteligencia competitiva: corpus teórico y prácticas. Recuperado de http://web.a.ebscohost.com.talamanca.uned. ac.cr/ehost/pdfviewer/pdfviewer?vid=7ysi$d=3 d 172 a 3 c-5858-4 b 34-8 d b 4-06 d f a 36 e 96 c-$ b\%40sessionmgr4010yhid=4106

Hill, C., y Jones, G. (1996). Administración Estratégica un enfoque integrado. Colombia: McGraw-Hill.

Kotler, P. (1992). Dirección de Marketing. Madrid: Prentice Hall.

Ley N07664. Ley de Protección Fitosanitaria. Recuperado de http://www.cnaacr.com/docs/ LEY-7664-LEY-DE-PROTECCION-FITOSANITARIA.pdf

Lopez, E. (1986). La diferenciación de Productos Agrarios. Madrid: Instituto de Economía Agraria y Desarrollo Rural del C.S.I.C.

Lombana, J., y Rozas, S.(2009) Marco Analítico de la competitividad Fundamentos para el estudio de la competitividad regional. Recuperado de http:// www.redalyc.org/articulo.oa?id=64612291002

Mata, G. (2007). Reflexiones sobre la Planificación Estratégica. Revista de Economía y Derecho, 4(16), 46-56.

Ministerio de Hacienda de Costa Rica. (s. f.). Ley General de Aduanas. Recuperado de http://www.hacienda.go.cr/docs/51c9baa1 b805f_LEYGENERALDEADUANASACTUALIZADAAOCTUBRE2012.pdf

Miles, R., y Snow, C. (1978). Organizational strategy, structure and process. New York: McGraw- Hill.

Mintzberg, H. (1978). Patterns in strategy formation. Management Science, 24(9), 934-948.

Mintzberg, H. (1988). Generic Strategies: Toward a Comprehensive Framework. Advances in Strategic Management, 5, 1-67. Greenwich, Ct: Jai Press.

Pérez, M., y García, J. (1997). Perspectivas para juzgar la estrategia de la unidad estratégica de nego- cio: una visión integradora. Cuadernos de Estudios Empresariales, 7, 273-286.

Porter, M. (1980). Competitive strategy. Techniques for analyzing industries and competitors. New York: The Free Press.

Porter, M. (2010). ¿Qué es estrategia? [video publicado el 23 setiembre 2010] Recuperado de https:// www.youtube.com/watch?v=0E0e6NqcT0M

Ramírez, M. (2004). Manual agricultura alternativa: principios. Colombia: Quebecor World Bogotá, S.A.

Robinson, W. (1990). Sources of Market Pionner Advantages: The Case of Industrial Goods Industries. Journal of Marketing Research, 25, 87-94.

Robbins, S. (2004). Comportamiento organizacional. México: Pearson Educación.

Roque, A., y Pierdant de la Mora, P. (1996). Prácticamente CÓMO EXPORTAR. México: Plaza y Valdés.

Rozas, S., Corredor, C., Lombana, J., Silva H., Castellanos, A., González, J. y Ortíz, M. (2013). Negocios internacionales: fundamentos y estrategias. Colombia: Universidad del Norte.

Sistema Costarricense de Información Jurídica. (s. f.). Reforma Ley General de Aduanas No8373. Recuperado de http://www.pgrweb.go.cr/scij/ Busqueda/Normativa/Normas/nrm_texto_completo.aspx? param $1=$ NRTCynValor1 $=1 \mathrm{ynVa}-$ lor2=51413ynValor3=55549ystrTipM=TC

Tonietto, J., Sotés, V., y Gómez, M. V.D. (Ed.). (2012). Viticultural climate and climatic groups in Ibero-Amercian wine producer regions. Madrid: CYTED, 401-411.

Whetten, D., y Cameron, K. (2011). Desarrollo de habilidades directivas. México: Pearson.

Recibido: 09 de setiembre de 2017 Aceptado: 05 de marzo de 2018 